\title{
Ponencia presentada en el Segundo Encuentro de Profesionales de la Salud
}

Hotel Tequendama. Diciembre 3/2002

Aida Navas de Serrato*

Al dirigirme a ustedes, por honrosa distinción de la Confederación de Organizaciones de Profesionales de la Salud, COPSA, quisiera, en primer lugar, hacer llegar un afectuoso saludo de felicitación a los profesionales de la Medicina en la celebración del Día Panamericano del Médico.

La Confederación creada en 1976 agrupa a las siguientes Asociaciones Científicas: Federación Odontológica Colombiana, Asociación Colombiana de Fisioterapia, Asociación Sindical de Trabajadores Sociales, Federación Colombiana de Optometría, Asociación Colombiana de Nutrición y Dietética, Colegio Nacional de Bacteriólogos, Asociación Colombiana de Fonoaudiología y Terapia del Lenguaje, Colegio Nacional de Químicos Farmacéuticos, Asociación Colombiana de Medicina Veterinaria y Zootecnia, Asociación Colombiana de Facultades de Fisioterapia y Asociación Colombiana de Terapia Ocupacional.

Sus objetivos son promover, impulsar, respaldar y defender para sus asociados el desarrollo del ejercicio profesional autónomo, responsable y efectivo y generar todas aquellas acciones que garanticen el reconocimiento de su valiosa intervención para la salud del país y sus gentes, por parte del Estado y de las instituciones.

Cumplir estas metas ha implicado un proceso de tiempo, que nos ha llevado a romper paradigmas, a satisfacer con la evidencia científica, social y humana la real

\footnotetext{
* Terapeuta Ocupacional Universidad Nacional. Presidenta de la Asociación Colombiana de Terapia Ocupacional. Vicepresidenta Asorreforma Ley 100/93.
} 
importancia de nuestro accionar profesional, a lograr que desde el Ministerio de Salud los proyectos y documentos no solamente se escriban en términos médicoquirúrgicos, muy importantes pero no únicos. También hace parte de un continuo, genuino y empecinado deseo por hacer evidente que no sólo somos colaboradores, que no somos paramédicos, prefijo este, que le permitió a uno de nuestros políticos en desafortunada intervención afirmar que así como había paramédicos que le ayudaban a los médicos también había paramilitares que ayudaban a los militares, sino que, desde la particularidad de nuestra formación profesional y de los procedimientos que utilizamos trabajamos en una relación interdisciplinaria transversal, coordinada y dinámica, que respeta las jerarquías en tanto ellas respondan a esquemas de organización que validan la pluralidad del conocimiento, básicamente, porque esto va a incidir de manera positiva en el mejor estar y en el bienestar de la persona o grupo poblacional objeto de nuestra intervención.

El trabajo conjunto de nuestras asociaciones, representado en COPSA, con las organizaciones de profesionales de la medicina en sus diferentes especialidades alrededor de los postulados de ASOREFORMA se constituye entonces en una iniciativa multifactorial y proactiva que centra su gestión en el hecho insoslayable de la necesidad de establecer mecanismos, hacer propuestas y llegar a acuerdos que aseguren la revisión de la Ley 100 de 1993. Queremos creer en la posición del Gobierno al manifestar su reconocimiento como interlocutores a un número inmenso de profesionales de diferentes disciplinas que han asumido su responsabilidad no sólo como actores diarios en el difícil arte de proporcionar salud y aliviar la enfermedad, sino como colectivo pacífico, pensante y dialogante que quiere, con la fuerza de las ideas, asegurar la exigibilidad de los derechos económicos, sociales y culturales de la población, representados aquí en el derecho a la salud.

Este movimiento no es sólo una unión de voluntades ni puede ser solamente el resultado de frustraciones acumuladas en el doble proceso de obtener y proporcionar salud y calidad de vida a nuestros conciudadanos. El doctor Mario Hernández Álvarez en su documento: "El derecho a la salud en Colombia: obstáculos estructurales para su realización", del cual dice que puede resultar incómodo para los optimistas, analiza, entre otros aspectos, lo que ha sido la intervención de los actores del sistema de salud en el debate sobre la Ley 100, mencionando que ni EPS ni ARS están dispuestas a suspender sus privilegios, que tanto los profesionales de la salud como los sindicatos de trabajadores de la salud han debatido sobre propuestas en las cuales se señalan como damnificados de la reforma planteando cambios 
al sistema de salud sin llegar a acuerdos definitivos y que finalmente los planes de desarrollo de los gobiernos en general se han orientado a resolver las serias dificultades en cuanto a viabilidad y estabilidad financiera que presenta hoy el sistema.

No es extraño entonces encontrar profesionales escépticos, acomodados a sus dificultades y a las graves carencias del país en materia de salud, y funcionarios para los cuales el problema es cuestión de algunos ajustes.

Por eso, aunque suene a lugar común, no podemos ser inferiores al reto que nos hemos planteado; más allá de poder obtener prebendas personales, éste es un compromiso entre individuos, sociedad y nación para poder entender y pensar un sistema en el que la salud como derecho y como calidad de vida sea la base del bienestar de los individuos y el firme soporte del desarrollo social y económico del país.

Es necesario reconocer e involucrar la salud en el concepto de desarrollo y así lo han hecho países como Costa Rica, China, Sri Lanka y Cuba que cuentan con sistemas de salud fuertes e índices de salud similares a los de países desarrollados.

En términos de salud, las políticas deben abarcar los diferentes niveles de protección de este derecho, desde la promoción y prevención hasta el tratamiento y rehabilitación.

En esta última fase, la de tratamiento y rehabilitación, quiero hacer algunas reflexiones que están particularmente ligadas a las políticas de atención y al evidente incremento de los niveles de discapacidad de la población.

Si entendemos la discapacidad como una alteración de la calidad de vida, su incidencia en los parámetros de salud está generada por el incremento en las tasas de enfermedades, incremento de embarazos en adolescentes y en madres con mínimos niveles de nutrición y protección, altos índices de desnutrición en la población infantil que determinan alteraciones definitivas en el desarrollo y consecuentemente bajos niveles de desempeño en los procesos de aprendizaje y rendimiento escolar, incremento en las tasas de enfermedad mental como consecuencia del entorno de violencia intrafamiliar, social y del conflicto armado y bajos niveles de protección a la población de adultos mayores en condiciones de pobreza.

Igualmente, las enfermedades crónicas y degenerativas, las secuelas de traumas y los efectos devastadores de la violencia incrementan los índices de discapacidad y 
representan para la nación una pérdida no cuantificable en términos de años de vida potencialmente perdidos y años de vida saludable perdidos.

Para Sara Rodríguez, terapeuta ocupacional experta en el desarrollo de proyectos para atención a la discapacidad, nadie está exento de encontrarse, en un momento de su ciclo vital, con una alteración en su capacidad funcional para ver, oír, hablar, moverse o caminar, cuidar de sí mismo o relacionarse con los demás, por lo cual existe una prevalencia de personas en situación de discapacidad y minusvalía en una comunidad.

Esta alteración de la capacidad funcional, como consecuencia de deficiencias de distintos grados de severidad, en la apariencia, función o estructura del sistema orgánico, ocasiona enormes costos personales, familiares sociales y económicos, al excluir del Sistema de Seguridad Social a las personas con discapacidad.

Desde otra perspectiva de la situación, el estudio descriptivo de los doctores Aldemar Jutinico Vega y Óscar Ashley Buitrago sobre la discapacidad física, psicológica y laboral causada por el conflicto armado, realizada entre enero y mayo de $2001 \mathrm{con}$ una población de estudio de 240 militares y 75 ex guerrilleros con discapacidad, señala que existe un grave desconocimiento del problema, razón por la cual las políticas y programas de prevención y rehabilitación integral tienen enfoques meramente asistenciales que subestiman $e$ inhiben las capacidades $y$ aportes a la sociedad de estas personas.

La rehabilitación física de estas víctimas del conflicto armado se realiza de manera incompleta e irregular centrada especialmente en las intervenciones quirúrgicas; pero los tratamientos de rehabilitación son deficientes y muchas veces el acondicionamiento de sillas de ruedas, bastones y muletas no tiene entrenamiento previo. La rehabilitación psicológica no se da como un programa de rehabilitación funcional que responda con continuidad y efectividad a los efectos del impacto del estrés postraumático en el estado de salud mental. El programa de rehabilitación ocupacional no define los perfiles ocupacionales de los discapacitados y las iniciativas existentes se pueden clasificar como proyectos de generación de empleo basados en la asignación de subsidios, pero con recursos de capital y asistencia técnica insuficientes.

Aunque el estudio señala que no pretende hacer generalizaciones o inferencias absolutas, sí es claro al recomendar que a través del Plan Nacional para la 
Discapacidad se implementen programas sostenibles y continuos para esta población y para los niños víctimas de minas antipersonales.

Ante esta situación de incremento en los niveles de discapacidad, consideramos prioritario asegurar la viabilidad de las políticas y lineamientos que desde el Gobierno están propuestas en el Plan Nacional de Atención a la Discapacidad y que plantean un manejo global de la prevención, la habilitación/rehabilitación y la equiparación de oportunidades.

Resulta necesario establecer un registro sistemático que permita cuantificar los niveles de discapacidad y su prevalencia.

Desde la normatividad de la Ley 100 aunque se reconocen los beneficios a que tienen derecho las personas con discapacidad, en uno de sus parágrafos se regula que el Ministerio de Salud y el Consejo Nacional de Seguridad Social en Salud determinarán los beneficios a que tendrán derecho los limitados de escasos recursos no afiliados, hasta el año 2001 , fecha en que la cobertura será universal.

El POS excluye de sus beneficios las sillas de ruedas y elementos de órtesis y prótesis, audífonos y aquellas actividades, procedimientos e intervenciones de carácter educativo, instruccional o de capacitación que se lleven a cabo durante el proceso de rehabilitación, distintos a aquellos necesarios estrictamente para el manejo médico de la enfermedad y sus secuelas. La norma hace que en la mayoría de las EPS, que tienen centros de atención en rehabilitación, los programas estén destinados a atender rápidamente los eventos y no a implementar conjuntos de acciones en rehabilitación que aseguren la recuperación de la independencia funcional.

Sobre la base de lo anterior, la atención a la población con discapacidad, entendida como alteración en las condiciones biológicas, sensoriales y ocupacionales, debe estar centrada no sólo en el diseño de programas de atención sino en el fortalecimiento de los centros de rehabilitación en los tres niveles de atención y, básicamente, en la revisión de la normatividad que permita que los objetivos, lineamientos y acciones idealmente planteados desde los macroproyectos sean viables y efectivos en la cotidianidad de la atención, en el día a día y en la particularidad de los procedimientos para asegurar a cada niño, hombre y mujer colombianos la recuperación o adecuación de su potencial físico, mental, espiritual y ocupacional.

\section{CONSTRUYAMOS INDIVIDUOS PARA PODER CONSTRUIR NACIÓN}

